\title{
The Role of Pedagogical Variables in Intercultural Development: A Study of Faculty-led Programs
}

\author{
Allison J. Spenader \\ College of Saint Benedict and Saint John's University (MN) \\ Peggy Retka \\ College of Saint Benedict and Saint John's University (MN)
}

\section{Introduction}

Study abroad is often regarded as an important curricular component for supporting intercultural development among college students. While creating rich cross-cultural experiences for students is of primary concern, it remains unclear exactly which programmatic features of study abroad influence intercultural growth in a positive way. Consensus seems to be building around the importance of quality interventions within study abroad programs. What those interventions might look like may vary by context, and researchers are beginning to delve into the task of exploring the salient features of effective mentoring and guided reflection within sojourns. This paper examines multiple semester-long study abroad programs that utilize a faculty-led model as a means of providing effective pedagogical interventions to support intercultural learning outcomes. This research works to reveal the impact of certain contextual, personal and pedagogical variables on intercultural development in study abroad.

In a recent compilation of research on learning outcomes of study abroad, Vande Berg, Paige and Lou (2012) review a myriad of issues facing the field of study abroad including: what students are actually learning, the academic rigor of academic coursework taken abroad, issues related to immersion, acculturation and the role of interpersonal relationships abroad, among other factors. In the past, much focus has been placed on how the design of a program influences learning outcomes. These studies considered personal and contextual factors such as housing type (Bachner, Zeutschel, \& Shannon, 1993; Knight \& Schmidt-Rinehart, 2002; Vande Berg et al., 2009), language proficiency (Freed, 1995; Paige, 1993; Vande Berg et al., 2009) and duration of study (Vande Berg et al., 2009). More recently, the field has seen a shift towards a recognition of the importance of thoughtful pedagogical interventions in maximizing the learning potential of study abroad programs. In their recent review of literature, Paige and Vande Berg (2012) focused their work on "intentional and deliberate pedagogical approaches" (p. 29) taken within study abroad programs. A new set of questions has surfaced around what effect interventions can have on learning outcomes, and what those interventions might look like. Our intention is to add to this growing body of literature by describing the findings of our own self-study on faculty-led, semester-long programs.

The College of St. Benedict and St. John's University (CSB/SJU) are two private Catholic (Benedictine) liberal arts colleges located in Minnesota. While CSB is a women's college, and SJU is an all-men's university, each with their own President and Board of Trustees, the schools operate under a shared academic mission, faculty governance and curriculum structure. The majority of the study abroad programs at our institutions utilize a faculty-led cohort program model in an effort to 
provide quality international experiences for students and faculty alike. This model serves our students well through a built-in cultural support mechanism during their time abroad. CSB/SJU offer 19 semester long programs (15 of which are faculty-led) on six different continents, and rank second nationally in semester-long study abroad participation among baccalaureate institutions, according to the 2013 Open Doors Report from the Institute for International Education (IIE).

With more than half of our students studying abroad during their college career, it is imperative that we understand the value of study abroad experiences in terms of intercultural learning outcomes. Vande Berg et al. assert that in judging the value of increasing study abroad programming on our college campuses, "What is all too often not addressed is whether core assumptions about student learning are warranted" (Vande Berg et al., 2012, p. 4). We must ask ourselves what the actual benefits to students are, and commit ourselves to inquiry that will help us improve the learning outcomes of the programs we offer. This self-study examines one important learning goal, intercultural development, as related to personal, contextual, and pedagogical variables.

\section{Literature Review}

It has long been assumed that study abroad affords students a wealth of positive learning outcomes. One such outcome that has received significant focus from both researchers and practitioners alike is the development of cross-cultural or intercultural skills. Benefits in terms of intercultural competencies have been the focus of numerous studies in recent decades, with Bennett's Developmental Model of Intercultural Sensitivity (DMIS) providing researchers with a useful model for describing intercultural development (Bennett, 1993; Paige et al., 2003). The Intercultural Development Inventory, or IDI, provides a highly reliable and valid tool with which to gauge the intercultural development of individuals (Hammer. et al., 2003). The most current version of the IDI, version 3, is based on Hammer's revisions to the DMIS which he calls the Intercultural Development Continuum, or IDC (Hammer, 2012).

Several recent studies have examined intercultural development in students studying abroad, using the IDI as the primary measure. Research has shown mixed results in terms of intercultural growth, indicating that simply spending time abroad is no guarantee for intercultural development. One of the largest IDI studies to date, the Georgetown Consortium study, investigated the intercultural gains of 1,163 secondary students in a wide variety of study abroad programs, and found an average gain of 2.37 points (Vande Berg et al., 2009). These IDI gains were "startling to anyone who had been developing and implementing study abroad programs of any type under the assumption and expectation that students were developing their intercultural competence by virtue of participation in study abroad alone" (Lou \& Bosley, 2012, pp. 339-340). Similarly modest average gains of just 2 points were found in another large scale study of AFS high school exchange students on a 10-month sojourn (Hammer, undated). Lou and Bosley explain that IDI gains of one or two points really should not be interpreted as a meaningful gain. Instead, gains in the order of 8 points signify a real shift, because they usually indicate a movement from one developmental stage to the next. Also important to note is that neither the AFS program nor the programs in the Georgetown Consortium study utilized a pedagogical model of cultural interventions or mentoring, aside for a small subset of participants in the Georgetown Consortium study that will be discussed later.

While the results of the two aforementioned studies may be described as disappointing, the findings of other researchers have shown impressive intercultural gains in some study abroad 
programs, as measured by the IDI. To further shed light on what seems to matter for intercultural development in study abroad, the Georgetown Consortium study examined IDI gains related to specific variables. Seven key variables were originally identified by Engle and Engle (2003), including: length of sojourn, entry target-language competence, language used in course work, the context of academic work, types of student housing, provisions for guided/structured cultural interaction and experiential learning, and the role of guided reflection on cultural experience (p. 8). Engle and Engle's classification of variables has proven useful for both exploring and describing programs (2003). While acknowledging the importance of personal variables (age and language competence), and contextual variables (where the program is located, length of sojourn, courses in target language, housing style, etc.), Paige and Vande Berg (2012) have decidedly focused their attention more recently on the specific role of several pedagogical techniques, including guided or structured cultural interactions and experiential learning, and guided reflection on cultural experience. They refer to these kinds of variables as programmatic factors. Paige and Vande Berg advocate for an increased focus on the role that these programmatic factors, which are largely pedagogical in nature, play in the learning and intercultural outcomes of study abroad. We hereby choose to use the term pedagogical to describe the deliberate intercultural experiences, assignments and reflections contained within the academic coursework in a study abroad program.

With a few exceptions, the results of the Georgetown Consortium study indicate that most of the Engle and Engle variables (personal and contextual) appear largely unrelated to intercultural growth. For instance, they found that students who studied abroad for a semester (13-18 weeks) made the greatest intercultural gains, on average 3.398 points, compared with students who studied abroad for as few as three weeks or as long as a year. For students studying in foreign language environments, those who had studied the target language since high school showed the greatest intercultural gains, compared to students who had studied less of the target language. IDI scores were also significantly higher among students who took coursework in the target language when compared to those who took courses in English. The Georgetown Consortium study students who took classes with other U.S. nationals made greater intercultural gains than those who took classes comprised only of host country students. Considering the role of student housing, the Georgetown Consortium study did not find intercultural gains for students living with host families, nor for those living with other international students. However, students who lived with other U.S. nationals, or with host national peers (not in homestays) showed higher gains on the IDI.

More significant appears to be the impact of specific pedagogical variables, what Paige and Vande Berg (2012) call programmatic factors, on intercultural development. One striking finding was the significant intercultural gains made by one group included in the Georgetown Consortium study in particular. While the study reported a relatively small sample of programs utilizing group mentoring while in country, they did find that students who participated in an ongoing series of mentored intercultural reflections experienced greater average intercultural gains (12.47 points) than those who did not (1.34 points). Several other studies have also found evidence to support the notion that interventions play an important role in intercultural development. Engle and Engle have studied the American University Center of Provence (AUCP) program extensively, and report impressive IDI gains. This program utilizes both linguistic and cultural mentoring throughout the semester or yearlong programs. The AUCP program reports average gains of 11.97 points in one of their semesterlong program sites $(n=414)$, and average gains of 10.81 in the other $(n=73)$ (Paige \& Vande Berg, 2012). Another program utilizing cultural interventions showing impressive intercultural gains is the 
Willamette University-Bellarmine University Intentional and Targeted Intervention program, which found that in programs that used an instructor-led model (as opposed to an online program), average IDI gains were 8.08 points. This was higher than the average gain of 6.65 points among the group using the non-instructor version of the course (Lou \& Bosley, 2012). Vande Berg et al. describe this type of pedagogical mentoring as "one of the single most important steps we can take in working to maximize students' intercultural learning..." (2009, p. 22). Based on these and other recent findings, Paige and Vande Berg call for increased attention on the issue of the impact of these kinds of interventions on intercultural development (2012). In their review of numerous studies utilizing an interventionist model, they conclude that mentoring from a trained cultural mentor is essential. This mentoring should include cultural content instruction, as well as reflection. They also recommend intentional, guided engagement with the new culture through internships or service learning projects. Furthermore, pre-departure and reentry experiences were also found to be important, and such experiences may be more effectively done in-person, rather than online. These conclusions offer us some useful guidance for what may be best practices in study abroad programming, and certainly warrant further investigation.

The Georgetown Consortium study findings also point to the importance of considering an additional variable with regards to intercultural development in study abroad programs (Vande Berg et al., 2009). Their study found support for Sanford's challenge/support hypothesis, which encourages us to work to create environments that provide enough challenge to students to keep them engaged, but also enough support to ensure that students do not retreat from the situation due to feeling overwhelmed (1966). The challenge/support hypothesis seems to echo the conclusions of Paige and Vande Berg; intentional guided engagement can help students encounter new challenges, while a cultural mentor can support the sojourner through these challenges (2012). Vande Berg et al. hypothesize that "the presence or absence of a well-trained cultural mentor who meets frequently with students may be the single most important intervention to improve student intercultural learning abroad" (2009, p. 25).

Recently, attention has been paid to the benefits that experiential learning may hold for intercultural growth in sojourners (Passarelli and Kolb, 2012). They note that experiential learning in a study abroad context holds great potential for learning because students living in an unfamiliar environment must learn to "adopt new ways of thinking, acting and relating to the world" (p. 137). Researchers Kolb and Kolb (2005) note that the space within which experiential learning is happening is critically important, and that it needs to be a learning space that is challenging and supportive. Furthermore, they stress that the learning space should make the individual responsible for their own learning experience, and provide time for both practice and reflection in order to build knowledge. As we work to understand the value of delivering study abroad programs through a faculty-led model, it behooves us to further investigate how specific pedagogical approaches, including experiential learning, can support greater intercultural development.

\section{Research Methods}

\section{Study Design}

This study investigates the intercultural development of undergraduate participants in several CSB/SJU programs abroad, using the Intercultural Development Inventory (IDI) as the means of evaluation. Pre- and post-test IDI scores allow for a comparison between various cohorts and 
programs to allow us to explore what role programmatic and pedagogical variables play in intercultural development. This study includes data collected between 2010 and 2013 on 121 students who studied abroad in a variety of programs, representing an array of academic majors at our institutions.

\section{Research Questions}

Q1: What is the relationship between contextual and personal variables and intercultural development in the programs studied?

Q2: What is the relationship between pedagogical variables and intercultural development in the programs studied?

All participants in selected study abroad programs were invited to participate in the study. The programs chosen for inclusion in the study represented several key features that we as investigators were interested in studying, including English vs. foreign language programs, varying housing models and differences in the academic course types offered. Intercultural development was measured using the IDI (Hammer \& Bennett, 1998). Participants completed a pretest IDI approximately one month prior to departure, and a posttest IDI about a month following their return. The IDIs were completed using Version 3 IDI, administered online. Data was analyzed using paired t-tests to compare the changes in IDI scores between groups.

\section{Context: Programs included in the study}

Below we include brief summaries of each program included in this study. As a framework, we have focused these descriptions around key contextual, personal and pedagogical variables. Three of the variables remain consistent across the programs:

- The length of sojourn is one US semester (approximately 14 weeks);

- The provisions for guided/structured cultural interaction and experiential learning are provided by CSB/SJU's Common Curriculum learning goals; and

- The role of guided reflection on cultural experiences, as facilitated by the Faculty Directors, is incorporated into the Study Abroad Seminar course.

The remaining program design variables of entry target-language competence, language used in course work, the context of academic work, and types of student housing are detailed in Table 1. 
Table 1. Contextual and Personal Variables by Program

\begin{tabular}{llll}
\hline Program & Language Requirement & Coursework & Housing \\
\hline Chile & $\begin{array}{l}\text { 5 semesters of college level } \\
\text { Spanish }\end{array}$ & $\begin{array}{l}\text { Language and culture courses, in } \\
\text { Spanish, with international } \\
\text { students. May take one or two } \\
\text { courses with local students. }\end{array}$ & Homestay \\
\hline Guatemala & $\begin{array}{l}\text { 3 semesters of college level } \\
\text { Spanish }\end{array}$ & $\begin{array}{l}\text { Language and culture classes, in } \\
\text { Spanish, for CSB/SJU students } \\
\text { only }\end{array}$ & Homestay \\
\hline Ireland & None & $\begin{array}{l}\text { Various topics, for CSB/SJU } \\
\text { students only }\end{array}$ & With peers from \\
\hline South Africa & None & $\begin{array}{l}\text { Various topics, almost exclusively } \\
\text { for CSB/SJU students }\end{array}$ & $\begin{array}{l}\text { With peers from } \\
\text { CSB/SJU }\end{array}$ \\
\hline Spain & 6 semesters of college level & $\begin{array}{l}\text { Various topics, in Spanish, for } \\
\text { CSB/SJU students only }\end{array}$ & Homestay \\
\hline
\end{tabular}

\section{Chile}

Our program to Chile takes place in the seaside resort city of Viña del Mar, 70 miles from the capital of Santiago. All students live with host families. The language requirement for this program is completion of five semesters of college-level Spanish. Students choose from a variety of art, culture, history, politics and Spanish language classes offered specifically for international students (the majority of whom are US nationals), and have the opportunity to take one to two direct enrollment courses at our partner university. Most of the courses are offered in Spanish, but business majors are allowed to take a business course in English. Parts of the seminar is also taught in English.

\section{Guatemala}

Our program in Guatemala takes place in Quetzaltenango (Xela), the nation's second largest city. Students live in individual homestays. This program requires three semesters of college-level Spanish prior to departure and all students are required to participate in a five-week intensive language course at the start of their program (five hours per day, five days per week). The initial five weeks are followed by ten weeks of continued Spanish instruction. All language instructions is one-on-one. In addition, students choose from a variety of content courses focused on culture, anthropology, theater, history and politics. All of the courses are taught in Spanish with the exception of the seminar and the anthropology course. The topics courses, though offered at a local university, are exclusive to our group.

\section{Ireland}

Our program in Galway, Ireland is the most rural of all of our study abroad programs. Participants in the Ireland program do not live with host families, but rather in groups of five students in cottages located nine miles outside of Galway. In the field of international education, this program would be described as an "island program" because the students eat, sleep and take courses at this facility. Besides the study abroad seminar, courses offered in this program included Irish archeology, literature, history and theology courses. Each of these courses is only offered to our students. There is no language requirement for this program, but students receive introductory Irish Gaelic lessons. 


\section{South Africa}

Our South Africa program is located in Port Elizabeth, where students live in groups of five in holiday apartment rentals. Courses in marine biology, literature, music, human rights and politics are offered at our partner institution, but the make-up of the roster is almost exclusively CSB/SJU students. Service learning is a major component of this program (six to eight hours per week). There is no language requirement for this program and all courses are taught in English.

\section{Spain}

Our Spain program is located in Segovia, where students live in individual host families. This program has our highest language prerequisite: completion of six semesters of college-level Spanish and all courses are taught in Spanish. The content courses include art history, cinema, culture, history, politics and advanced Spanish language. All courses are exclusive to CSB/SJU students.

\section{Pedagogical Context: The faculty-led cohort model}

The semester-long programs included in this study are each led by a member of the CSB/SJU faculty who travel abroad with our students. These programs follow a cohort-design wherein students from our institutions travel as a group and take the majority of their courses together. No two programs are exactly the same in design, content and purpose, but there are common threads running throughout which serve to unify the experiences for our students.

Before departure, the faculty director is responsible for selecting the students, using a set of predetermined criteria (see Appendix A), and conducting pre-departure orientation sessions in conjunction with the Office for Education Abroad (OEA). While on-site, the faculty director serves as the primary contact for students, organizing a wide array of academic and logistical details, as well as teaching a seminar course focused on intercultural development and experiential learning while incountry. Guidance is provided for these faculty members in the form of learning goals set by the common curriculum of the institutions to ensure that the courses meet several designated intercultural learning goals:

1. Students will demonstrate a level of understanding of another culture, including the awareness that it is neither monolithic nor static.

2. Students will demonstrate an understanding that their perspective on the world is shaped in certain ways by their particular background.

3. Students will demonstrate an awareness that when we encounter another culture, we filter the new experience through established perspectives, which makes it more difficult to uncover our common humanity and the reasons for our differences.

Additionally, each seminar course meets learning goals that relate specifically to experiential learning. The experiential learning component requires that students learn independently by taking prior knowledge and skills and applying those in an experience that they have designed, and then reflecting on how the entire experience deepened their understanding of the prior knowledge. The stated learning goals for the experiential requirement are that students will:

1. Demonstrate the ability to integrate and apply knowledge and skills gained from one or more courses in activities that extend beyond the traditional classroom. 
2. Demonstrate specific ways in which the experiential-learning activities deepen their understanding of the knowledge and skills gained through traditional course work.

The intercultural and experiential learning goals met by these seminar courses are part of our institutional common curriculum for all students and are not unique to study abroad programs. Faculty directors are encouraged to design seminar courses that draw on their own scholarly expertise while meeting the required learning goals above and taking advantage of the specific resources and unique educational opportunities that their destination offers. This allows for an approach to intercultural education that draws on the interests and knowledge of the faculty member and takes advantage of the unique aspects of the host culture. Examples of seminar courses offered in our programs included The Legacies and Memory of the Pinochet Dictatorship (Chile 2010), Ethics through Irish literature and history (Ireland 2010) and The Catholic Reformation of Spain (Spain 2011). While this approach results in a diverse array of seminar topics, the shared intercultural and experiential learning goals provide a structure wherein all participants may engage in meaningful reflections about culture within their chosen context abroad.

Just as the topics of the seminar courses were unique to each program, the type of experiential learning projects vary by program as well. In some programs, students perform service to the local community. In Chile, for example, students may volunteer in classrooms at local schools, with a micro-financing program or other non-profits serving a variety of people. In South Africa, students perform service learning in one of three approved sites in the local townships: a primary school, an orphanage, or a community center. In other programs, the experiential learning project is a studentinitiated research project. These projects are designed in consultation with the faculty leader, and require students to engage with the local community (perhaps through interviews) in order to gain new understandings of the information they are studying in class. Finally, some experiential learning projects are student-initiated cultural explorations related to an individual research interests. 
Table 2. Pedagogical Focus by Program

\begin{tabular}{|c|c|c|}
\hline Program & Seminar Course Title & Experiential Learning Type \\
\hline \multirow[t]{2}{*}{ Chile } & $\begin{array}{l}\text { The legacies and memory of the Pinochet } \\
\text { dictatorship in Chile (2010) }\end{array}$ & Service Learning (20-25 hours) \\
\hline & $\begin{array}{l}\text { A Study of Contemporary Latin America through } \\
\text { Current Events and Cultural Observations of } \\
\text { Chile (2011) }\end{array}$ & Excursions connected to courses \\
\hline \multirow[t]{2}{*}{ Guatemala } & $\begin{array}{l}\text { Weaving Connections: The weft and waft of } \\
\text { intercultural understanding (2012) }\end{array}$ & Service Learning (20-25 hours) \\
\hline & & Excursions connected to courses \\
\hline Ireland & $\begin{array}{l}\text { Ethics through Irish literature and history (2010) } \\
\text { Ireland's People and Culture (2011) }\end{array}$ & Excursions connected to courses \\
\hline South Africa & $\begin{array}{l}\text { Exploration of Culture and Ethics in the context } \\
\text { of South Africa (2012) }\end{array}$ & $\begin{array}{l}\text { Service Learning (90 hours) } \\
\text { Excursions connected to courses }\end{array}$ \\
\hline \multirow[t]{2}{*}{ Spain } & The Catholic Reformation of Spain (2011) & Excursions connected to courses \\
\hline & $\begin{array}{l}\text { The Spanish Civil War, Social Change and } \\
\text { Memories (2012) }\end{array}$ & \\
\hline
\end{tabular}

The intercultural learning goals put an emphasis on reflecting on one's own cultural lens. Students must demonstrate an awareness of their own culture and the effect it has on their views of new cultures they encounter. Similarly, the experiential learning goals require student to apply new experiences and knowledge to create new understanding, which requires substantial reflection. Vande Berg et al. (2012) point out that "students learn and develop considerably more when educators prepare them to become more self-reflective, culturally self-aware, and aware of 'how they know what they know" (p. 21). This focus on building self-awareness and an appreciation for where prior understanding comes from is also reflected in the experiential learning goals in that students must integrate and apply prior knowledge in a new experiential context. The combination of intercultural and experiential learning goals present in each of the study abroad programs examined in this study reflect an intent to provide students with experiences abroad that are deeply meaningful and scaffolded with guided reflection and mentoring.

The faculty members who lead the programs at our institutions work to fashion seminar courses that draw on the local context for in-depth exploration of the topic of their choosing. Because faculty are encouraged to design courses that reflect their areas of scholastic expertise, there is much variation in the courses offered. This is true not only in course topic areas, but also in the design of assignments and experiential learning projects, approaches to discussion, and methods of assessment. While many contextual and programmatic variables can be carefully designed and controlled for, herein remains a large degree of variability. While the diversity in course offerings and expertise among the faculty leaders can be viewed as a great benefit to these programs, we also recognize that it may also present challenges in that there is variability in terms of the kinds of mentoring students receive in different programs. 
In addition to taking the seminar course, participants choose from a menu of other courses taught by local faculty at a partner institution or host university. Some of these courses are designed specifically for our students, fulfilling a particular CSB/SJU general education or department specific curriculum. In most of these courses, host country students are not enrolled. A second model of courses are those offered by a third-party provider whom we partner with to offer our study abroad options. In many cases, these courses are open to the CSB/SJU students as well as other US and international students who have also enrolled at these institutions. The final option for coursework is a direct enrollment option where students choose from a catalog of courses offered to the host country students and our students join their regular university classes. All of the above models offer language classes, content courses taught in English, and content courses taught in the target language in our foreign language settings.

\section{Results}

Pre-test and post-test scores on the IDI were compared to measure intercultural development of the students across the programs mentioned above. In looking at intercultural change as measured by the IDI, we are looking only at the Developmental Orientation (DO) scores. The IDI instrument also provides what is called a Perceived Orientation (PO) score, but we are not considering that score in this data set. While there was no significant statistical difference between groups of participants in terms of their pre-departure IDI scores, some variation was observed that seems to indicate that different programs were attracting students of differing intercultural development levels. The Chile 2010 cohort began with the lowest pre-test IDI scores (polarization stage), followed by Spain 2012 (cusp of minimization). All other groups began their programs in the minimization stage; although there was plenty of in-group variation (individual students began anywhere from defense to acceptance). Despite this variation, the lack of statistical significance between the groups indicates that all participants began the study with similar levels of intercultural development. While this rules out any self-selection bias that might have been present between students who chose certain programs over others, there may nonetheless be some patterns of difference between students who select one program over another. 
Table 3. Overview of IDI Mean Scores and SDs by Program

\begin{tabular}{|c|c|c|c|c|c|c|}
\hline Program & $\begin{array}{l}\text { Number of } \\
\text { participants }(\mathrm{N})\end{array}$ & $\begin{array}{l}\text { Group pretest mean IDI } \\
\text { DO }\end{array}$ & $\begin{array}{l}\text { Standard } \\
\text { Deviation }\end{array}$ & $\begin{array}{l}\text { Group posttest mean } \\
\text { IDI DO }\end{array}$ & $\begin{array}{l}\text { Standard } \\
\text { Deviation }\end{array}$ & $\begin{array}{l}\text { Group change } \\
\text { score }\end{array}$ \\
\hline Chile 2010 & 12 & $\begin{array}{l}81.72 \\
\text { (Polarization) }\end{array}$ & 10.02 & $\begin{array}{l}91.78 \\
\text { (Minimization) }\end{array}$ & 13.22 & $+10.06^{\star}$ \\
\hline Ireland 2010 & 21 & $\begin{array}{l}86.62 \\
\text { (Minimization) }\end{array}$ & 9.98 & $\begin{array}{l}88.18 \\
\text { (Minimization) }\end{array}$ & 10.99 & +1.57 \\
\hline Spain 2011 & 18 & $\begin{array}{l}88.72 \\
\text { (Minimization) }\end{array}$ & 15.95 & $\begin{array}{l}93.80 \\
\text { (Minimization) }\end{array}$ & 10.63 & +4.31 \\
\hline Chile 2011 & 14 & $\begin{array}{l}90.47 \\
\text { (Minimization) }\end{array}$ & 6.21 & $\begin{array}{l}99.13 \\
\text { (Minimization) }\end{array}$ & 13.20 & $+8.65^{*}$ \\
\hline Ireland 2011 & 13 & $\begin{array}{l}91.63 \\
\text { (Minimization) }\end{array}$ & 12.27 & $\begin{array}{l}90.14 \\
\text { (Minimization) }\end{array}$ & 17.60 & -1.48 \\
\hline Spain 2012 & 10 & $\begin{array}{l}83.52 \text { (Cusp of } \\
\text { Minimization) }\end{array}$ & 13.56 & $\begin{array}{l}84.22 \text { (Cusp of } \\
\text { Minimization) }\end{array}$ & 12.48 & +.70 \\
\hline $\begin{array}{l}\text { South Africa } \\
2012\end{array}$ & 22 & $\begin{array}{l}89.08 \\
\text { (Minimization) }\end{array}$ & 15.11 & $\begin{array}{l}98.56 \\
\text { (Minimization) }\end{array}$ & 14.20 & $+9.38^{\star}$ \\
\hline $\begin{array}{l}\text { Guatemala } \\
2012\end{array}$ & 11 & $\begin{array}{l}90.40 \\
\text { (Minimization) }\end{array}$ & 11.17 & $\begin{array}{l}98.56 \\
\text { (Minimization) }\end{array}$ & 16.01 & +8.17 \\
\hline TOTAL & $N=121$ & $\begin{array}{l}87.77 \\
\text { (Minimization) }\end{array}$ & 11.78 & $\begin{array}{l}93.05 \\
\text { (Minimization) }\end{array}$ & 13.54 & +5.17 \\
\hline
\end{tabular}

*statistically significant gain $p>.05$ 
Intercultural growth was found among all but one group in the study; although the magnitude of gain varied from program to program. Compared to the mean IDI gain of 3.398 points of programs of comparable length (13-18 weeks) in the Georgetown Consortium study (Vande Berg et al., 2009), our programs produced an average mean IDI gain of 5.17. The greatest intercultural gains were seen in the South Africa, Chile and Guatemala program participants, while the most modest gains were found in the Spain and Ireland programs, with our 2011 Ireland group losing ground on the IDI. Both Chile 2010 and 2011, as well as South Africa 2012, produced statistically significant gains compared to the other study abroad program groups. The Guatemala group also made impressive gains, although it was not found to be statistically significant, likely due to the small cohort size. According to Lou and Bosley, gains in the range of 8 points or more indicate a meaningful improvement in intercultural development, often indicating a shift from one stage to the next (2012). By this measure, we see highly satisfactory intercultural growth in our South Africa, Chile and Guatemala program participants.

What explains the variability between the programs studied? In order to understand why some programs produce impressive intercultural gains while others don't, we will briefly examine both contextual and personal variables, followed by pedagogical variables.

\section{Contextual and Personal Variables}

Do the contextual and personal variables explain the variation in IDI scores found in our programs? In short, the answer is, not really. Because all of our participants were about the same age, 20-22 years old, we did not analyze our data in terms of the age of participants. All of the programs studied were between 13 and 16 weeks in length, and no correlation was found between the length of these programs and IDI gains. Just as the Georgetown Consortium study found that semester-long programs yielded the greatest intercultural growth, we found significant growth in several of our semester-long programs. We also found a mean gain in IDI score larger than the one found in comparable programs in the Georgetown Consortium study for most of our programs. The exceptions being the Ireland program, and one of the Spain cohorts, for which very modest gains, or even losses, were found.

We were curious to know more about the intercultural development that occurs in foreign language settings, as well as in English-language settings abroad. The role of language competency falls under the category of a personal variable. We found that language did not seem to account for variations in intercultural gains as measured by the IDI. The two program sites with the highest intercultural gains represented an English-speaking nation, South Africa, and a Spanish-speaking one, Chile. Our program with the lowest intercultural gains was Ireland, followed by Spain, a Spanishspeaking country.

All three of our Spanish language programs required some level of proficiency in the target language prior to departure. The Spain program has the highest proficiency requirement, but produced the most modest intercultural gains. These findings are in line with previous research citing no apparent relationship between entry target language proficiency and intercultural gains (Vande Berg et al., 2009).

Our study found no clear relationship between the language used in coursework and intercultural gains on the IDI. Looking at our Spanish-language programs, the Spain cohorts had the 
most modest IDI gains, but took all of their content courses in Spanish. Taking an additional Spanish language class was an option, but relatively few students took advantage of it. The Guatemala program, which showed good IDI gains, is a program that is focused on Spanish language proficiency development and offers content courses in Spanish as an option, rather than a requirement. The program that required both an advanced language course and content courses in Spanish, our Chile program, yielded the most impressive IDI gains of the three Spanish-language programs. Perhaps the required combination of language and content courses provides the optimum support and challenge needed for intercultural gains, but our data set does not show clear evidence of this. We posit that this may be a worthwhile relationship to investigate in future research.

We found no direct relationship between intercultural development and the kinds of academic programs of study offered by various programs. The two programs that yielded the greatest intercultural gains represent two very different academic program models. In Chile, students took coursework not only with peers from their home institutions, but with other U.S. nationals from other programs. Students in the Chile program generally did not directly enroll or take courses with Chileans, although a small number did choose to do so. The South Africa participants' courses were designed and delivered exclusively to them, without any peers from the host or other cultures. The South Africa model for academic coursework was similar to the Ireland, Spain and Guatemala programs, further indicating that this model can either be associated with impressive intercultural gains such as were found with the South Africa and Guatemala cohorts, or not.

Much like the academic program models, housing models were not found to be correlated to intercultural development. Our two most successful programs in terms of intercultural development, Chile and South Africa, utilized two very different housing models. In Chile, students were housed with host families in which there was usually a sibling close in age to the student living at home. In South Africa, students resided in apartments shared with their peers from our institution. Yet both of these models proved amenable to intercultural growth. The homestay environment may also have supported intercultural growth in students in Guatemala, but did not do so for students in Spain. Similarly we saw students living in shared apartment cottages in Ireland making very modest IDI gains, and even losses, while students in a similar housing environment in South Africa made significant gains.

\section{Pedagogical Variables}

All of these programs utilized a study abroad seminar to provide structured cultural interactions, experiential learning and opportunities for reflections with a faculty mentor. The seminar courses were designed to meet both intercultural and experiential learning goals, and were approved by an institutional committee to ensure that those goals would be met prior to being taught. Yet our data suggests that these standards alone do not ensure that all students will experience intercultural growth in their study abroad programs.

Differences were found between programs using a service model of experiential learning when compared to those that did not. In the Chile, South Africa and Guatemala programs, sojourners participate in a service project alongside host nationals. These kinds of experiential learning projects are associated with greater intercultural gains, perhaps because they provide a more meaningful series of interactions with the host community. On the other hand, programs using non-service type experiential learning projects, such as individual research or student-initiated cultural explorations 
(Ireland and Spain), had much more modest or negative intercultural gains.

It seems that pedagogical variables, which many believe to be the most critical component in intercultural development, are highly complex and merit further investigation in order to isolate which techniques may be the most effective. Vande Berg et al. warn us that even though we may believe that we have designed experiential activities that would allow our students to naturally engage with their hosts, students may still fail to learn because there is not enough structured guidance surrounding those experiences (2009). Our data suggest that even though programs are designed with specific experiential and intercultural learning goals in mind, this is no guarantee of intercultural development.

We are left wondering what pedagogical elements of the seminar courses offered warrant further development. It is likely that some aspects of the course, including the kinds of assignments, reflective exercises, and discussion formats influence the impact of individual cross-cultural growth. In particular, it appears that the kind of experiential learning project that students complete in study abroad can significantly impact intercultural learning.

\section{Discussion}

The study abroad participants in our programs, on the whole, made intercultural gains as measured by the IDI. However, we found variation between programs and even individual cohorts. While most of our programs produced what we considered to be good or even excellent IDI gains, we found little to no gain in our Ireland cohorts, and modest gains among our Spain cohorts. In examining each of seven program variables put forth by Engle and Engle (2003), we were unable to pinpoint any that definitively explained our IDI results. The question remains as to whether the variation between groups can be accounted for by any particular set of variables. Further complicating our task is the fact that individual sojourners bring their own sets of personality traits to the equation, variables for which we cannot control. Despite these challenges, the areas which seem most promising in their ability to account for variation in intercultural development are that of guided/structural cultural interaction and experiential learning, and the role of guided reflection on cultural experiences.

In considering the pedagogical variables of guided cultural interactions, experiential learning and guided reflection, we are left with more questions than answers. While all of our seminar courses were designed to meet the institutional, intercultural and experiential learning goals, we found great variation in terms of which ones produced intercultural gains as measured by IDI. Considering Sanford's Challenge/Support hypothesis (1966), it appears that some of our programs are striking an appropriate balance between challenge and support in terms of intercultural experiences, experiential learning and cultural mentoring. Yet some of our programs, namely Ireland and Spain, may not be presenting sufficient challenges or sufficient supports, or perhaps both are lacking. We are left with a number of additional questions. For example, which kinds of service learning projects might be most beneficial? What role does the individual faculty member play in providing support and mentoring? Does the intercultural development of the faculty member matter? 
Support was found for the impact that service-type experiential learning projects have on intercultural development. It seems that opportunities to work alongside host nationals leads to increased intercultural development. Guided reflection and the integration of new knowledge with existing knowledge was required in all of the experiential learning projects, but it was within programs using a service learning model that this translated into greater intercultural gains. The programs with the smallest intercultural gains, Spain and Ireland, utilized an experiential learning project model that did not require sojourners to work together with host nationals in a meaningful service capacity. Even though all the experiential learning projects required student initiative, the integration of existing and new knowledge, and substantial reflection, experiential learning projects that utilize a service learning model, in particular, appear to support more robust intercultural growth.

Our results suggest that students benefit from the guidance of a cultural mentor who meets frequently with students to support intercultural and experiential learning. The cultural mentor should also guide sojourners in noticing and working through cultural challenges. The role of the faculty director should not be overlooked as a significant factor in the growth, or lack thereof, in intercultural development. This question leaves lots of room for future discussion as we explore ways to more consistently prepare our faculty to lead these programs and mentor students. Lou et al. stress the importance of guided reflection and cultural mentorship, and recommend that cultural mentors be trained "in the theory and practice of intercultural teaching and learning" (2012. p. 416).

Preparing faculty to lead study abroad programs is a complex endeavor. As Robinson notes in her essay on the scholarship of teaching and learning in study abroad contexts, "Because educators in higher education are rarely trained as teachers, instead having made their successes in literature, history, archaeology, computer science, and other specialized fields, they often benefit from and appreciate opportunities to learn about good practices" (2012, p. 250). While the faculty leading our programs received guidance in designing their courses from both the Office for Education Abroad, previous faculty directors, the Director of the Common Curriculum and our institutions' curriculum committee, additional professional development for these faculty members to assist them in terms of their pedagogy may be highly beneficial.

\section{Conclusions}

While our data shows impressive gains on the IDI for many of our programs and cohorts, our institution needs to consider the lack of intercultural development among participants in other programs. What changes should be made to programs to ensure intercultural gains for all students who study abroad? The faculty-led model affords us the opportunity to provide meaningful mentorship to students across our programs, yet we aren't always seeing the kinds of outcomes we are hoping for. Paige and Vande Berg's recommendations for interventions in study abroad appear to align closely with the learning goals we already have in place for these seminar courses (2012). In particular, we believe our seminars are providing a focus on cultural content, opportunities for guided reflection, engagement with the culture through the experiential learning projects, as well as predeparture and re-entry support. We believe that by focusing our attention on pedagogical variables, and specifically on the use of service learning projects and on the role of the faculty director as a cultural mentor, we will be able to improve intercultural development outcomes for more of our study abroad participants. 


\section{References}

Bachner, D. J., Zeutschel, U., \& Shannon, D. (1993). Methodological issues in researching the effects of U.S.-German educational youth exchanges: A case study. International Journal of Intercultural Relations, 17, 41-71.

Bennett, M. J. (1993). Towards ethnorelativism: A developmental model of intercultural sensitivity. In R. M. Paige (Ed.), Education for the intercultural experience ( $2^{\text {nd }}$ ed., pp. 21-71). Yarmouth, ME: Intercultural Press.

Engle L., \& Engle. J. (2003) Study abroad levels: Toward a classification of program types. Frontiers: The Interdisciplinary Journal of Study Abroad, 10, 219-236.

Freed, B. (Ed.). (1995). Second language acquisition in a study abroad context. Philadelphia: John Benjamins.

Hammer, M. R. (undated). Assessment of the impact of the AFS study abroad experience. Executive summary: Overall findings. Ocean City, D: Hammer Consulting, LLC. Retrieved May 20, 2014, from http://www.idiinventory.com/pdf/afs_study.pdf

Hammer, M. R. (2012). The Intercultural Development Inventory: A New Frontier in Assessment and Development of Intercultural Competence. In Vande Berg, M., Paige, R. M, \& K. H. Lou (Eds.) Student learning abroad: what our students are learning, what they're not, and what we can do about it (pp. 115-136) Sterling, VA: Stylus.

Hammer, M. R., \& Bennett, M.J. (1998). The Intercultural Development Inventory. Portland, OR: Intercultural Communication Institute.

Hammer, M. R., Bennett, M. J., \& Wiseman, R. (2003). Measuring intercultural sensitivity: The Intercultural Development Inventory. International Journal of Intercultural Relations, 27, 421443.

Knight, S. M \& Schmidt-Rinehart, B. C. (2002). Enhancing the homestay: Study abroad from the host family's perspective. Foreign Language Annals, 35(2), 190-201.

Kolb, A. Y., \& Kolb, D. A. (2005). Learning styles and learning spaces: Enhancing experiential learning in higher education. Academy of Management Learning and Education, 4(2), 193-212.

Lou, K. H. \& Bosley, G. W. (2012). Facilitating intercultural learning abroad: The Intentional, Targeted Intervention Model. In Vande Berg, M., Paige, R. M, \& K. H. Lou (Eds.) Student learning abroad: what our students are learning, what they're not, and what we can do about it (pp. 335-359) Sterling, VA: Stylus.

Open Doors Report, Institute for International Education (2012). Retrieved May 20, 2014, from http://www.iie.org/Research-and-Publications/Open-Doors/Data/US-Study-Abroad/LeadingInstitutions-Duration-Institutional-Type/2011-12

Paige, R. M. (Ed.). (1993). Education for the Intercultural Experience. Yarmouth, ME: International Press.

Paige, R. M. \& Vande Berg, M. (2012). Why students are not learning abroad. In Vande Berg, M., Paige, R. M, \& K. H. Lou (Eds.) Student learning abroad: what our students are learning, what they're not, and what we can do about it (pp. 29-58) Sterling, VA: Stylus.

Passarelli, A. M., \& Kolb, D. A. (2012) Using Experiential Learning Theory to Promote Student Learning and Development in Programs of Education Abroad. In Vande Berg, M., Paige, R. M, \& K. H. Lou (Eds.) Student learning abroad: what our students are learning, what they're not, and what we can do about it (pp. 137-161) Sterling, VA: Stylus.

Robinson, Jennifer M. (2012). Learning Abroad and the Scholarship of Teaching and Learning. In Vande Berg, M., Paige, R. M, \& K. H. Lou (Eds.) Student learning abroad: what our students are 
learning, what they're not, and what we can do about it (pp. 239-257) Sterling, VA: Stylus.

Sanford, N. (1966). Self and society: social change and development. New York: Artherton Press.

Vande Berg, M., Connor-Linton, J., \& Paige, R. M. (2009). The Georgetown Consortium Project: Interventions for Student Learning Abroad. Frontiers: The Interdisciplinary Journal of Study Abroad, 18, 1-75.

Vande Berg, M, Paige, R. M. \& Lou, K. H. (Eds.) (2012). Student learning abroad: what our students are learning, what they're not, and what we can do about it. Sterling, VA: Stylus. 